\section{EVALUATION OF ADAPTATION OF PHARMACEUTICAL FORMS IN A PEDIATRIC HOSPITAL IN MANAUS}

Eliane Pimentel Nóbrega ${ }^{1}$

Suely Oliveira Chagas ${ }^{2}$

Igor Rafael dos Santos Magalhães ${ }^{1}$

\title{
ABSTRACT:
}

Background: The pharmaceutical form adaptation of medicines for pediatric use is frequent in Brazilian hospitals due to the lack of suitable formulations for children. This practice has been defined as an unlicensed use. Objective: In the present study, a descriptive, quantitative and retrospective study covering different aspects related to pharmaceutical adaptation was carried out in a pediatric hospital in Manaus during the year of 2016. Methods: Through the data collection from the hospital records, the different pharmacological classes and pharmaceutical forms used and produced, some aspects of good handling practices and the standard operating procedures applied in these formulations were evaluated. In addition, the consultation of the availability of ready-made formulations in the national market as alternatives to the hospital's production process and the accomplishment of calculations to verify the price comparison were carried out. Results: In this study, diuretics were the most modified medicines $(15,4 \%)$. The most produced therapeutic agents were Potassium Chloride and the association Spironolactone and Hydrochlorothiazide (21.2\%). The ready liquid dosage forms of dexamethasone, potassium chloride, oseltamivir and midazolam were found in the search on the market. In addition, it has been found that, in the comparison between the production process and the market purchase, the adaptation is financially advantageous, according to the calculations made. Conclusions: Therefore, it is concluded that the adaptation of pharmaceutical forms is a reality in the studied hospital and the need to purchase the industrialized product or to adapt the pharmaceutical form must take into account not only the financial aspect but also other aspects such as demand, availability in the Market, pharmacotechnical aspects, safety, effectiveness, among other points.

Keywords: Pharmaceutical Preparations, hospitals, pediatrics

\section{INTRODUCTION}

Pediatric patients need more attention with respect to therapeutic management. The ideal pharmaceutical forms in their case are the liquid ones, not only due to better administration and ease of swallowing, but also by the possibility of adjusting the dose for specific treatments for each patient ${ }^{1,2}$.

However, the production of this type of formulations is not common because some drugs have little effectiveness when formulated in aqueous solution. A medicine that was modified for an extemporaneous, oral or topical preparation is defined in the scientific community as an unlicensed product. However, cutting a pill, grinding it and dissolving it to obtain its liquid form offers risks of error in the dosage administered, contamination of the formulation while handling, loss of formula stability, and the possibility of losing of the effective action of the drug by diluting the tablet in liquid forms such as syrups, due to incompatibilities and interactions $s^{3,4}$. The lack of licensed medicines for children is a worldwide reality, particularly in the case of hospitalized children. This results in a very common practice in several pediatric hospitals: the adaptation of pharmaceutical forms for administration in children ${ }^{4,5}$.
The availability of appropriate pharmaceutical forms for children would facilitate drug administration, increase the effectiveness of treatment and prevent losses, resulting in reduced health costs. Furthermore, the preparation of formulations would be recorded as having followed good manipulation practices, besides having been submitted to clinical trials that ensure safety, efficacy, stability and provide expiration dates 5,6 .

Some studies have shown that the need for pharmaceutical adaptation is a reality in Brazil, since adequate formulations for pediatric use are virtually absent. Costa5 carried out a bibliographic survey and a research with pediatricians from a public hospital in Fortaleza-CE to indicate which medicines used in pediatric hospitals present problems in their pediatric use. Problems were related to inadequate dosage or unavailability of suitable pharmaceutical forms. The results showed that medicines such as captopril, hydrochlorothiazide, spironolactone and baclofen, among others, present problems when used in pediatric patients.

Later, the study by Nunes ${ }^{7}$ compared the costs of adaptation of drugs in a University Hospital in Natal-RN with the costs of purchasing their liquid formulation, and the latter option actually proved to offer economic advantages in the case of $75 \%$ of the
1 Universidade Federal do Amazonas

2 Instituto de Saúde da Criança do Amazonas

Received: $18 / 10 / 2017$

Revised: 09/03/2018

Accepted: 26/03/2018

How to cite this article: Nobrega EP, Chagas SO e Magalhães IRS. Evaluation Of Adaptation of Pharmaceutical Forms in a Pediatric Hospital in Manaus. Rev. Bras. Farm. Hosp. Serv. Saúde, 9(1): 1-5, 2018.

Doi: $10.30968 /$ rbfhss.2018.091.005

Corresponding author:

Prof. Dr. Igor Rafael dos Santos Magalhães

Universidade Federal do Amazonas

Av. Gen. Rodrigo Octávio Jordão Ramos, 3000, Manaus. CEP: 69077-000. AM - Brasil imagalhaes@ufam.edu.br 
medicines studied. However, this study demonstrated that only $20 \%$ of the adapted medicines have liquid formulations available in the market but not standardized in the Hospital, and most of the adapted medicines (73\%) have no alternative formulation available for purchase.

Another study carried out at a pediatric hospital in Fortaleza - CE described problems related to manipulation, including the absence of a refrigerator exclusively for storage of the prepared medicines, lack of adequate protection of the manipulator, including the use of gloves and masks, and absence of adequate tools and containers for grinding solid pills, evidencing the need for more rigorous attention ${ }^{3}$. According to a study carried out in a pediatric hospital in Manaus-AM, 6.3\% of the drugs prescribed in 2015 had their use classified as unlicensed; the most often prescribed were omeprazole, ranitidine and captopril ${ }^{8}$.

Although research has been done on pharmaceutical adaptation in different hospitals in Brazil, no studies on this topic were found in the North. The present study comprehensively evaluated several aspects related to drug manipulation in the health unit, contrasting the procedures performed with the current literature ${ }^{9}$ and verifying the existence of approved formulations available in the Brazilian market which would guarantee the efficient and safe treatment of patients when conducting specific clinical trials for infant physiology. The current procedure was also evaluated in economic terms based on the comparison between the cost of adaptations made at the pediatric hospital and ready-made formulations available in the Brazilian market, aiming at saving the public budget, and thus determining the best alternative for the treatment of pediatric patients of the referred hospital.

\section{METHODOLOGY}

The study was conducted at the Pharmacy Department of the Institute of Child Health in Amazonas (ICAM), a pediatric hospital located in the city of Manaus - Amazonas. A descriptive, quantitative and retrospective study was carried out, in which the records of pharmaceutical formulations produced at the Pharmacy Department between January and December 2016, and Standard Operating Procedures regarding the formulations produced, were evaluated. All the pharmaceutical adaptations made during the period mentioned, including medicines under special control and topical medicines, were included.

Through these data, all the drugs produced in the period analyzed were listed, and the most frequently adapted pharmacological classes and therapeutic agents were determined, listing the most frequently produced pharmaceutical forms and identifying high-alert medications ${ }^{10}$ and those subjected to special control that are adapted ${ }^{11}$.

The Anatomical Therapeutic Chemical - ATC methodology was used for the therapeutic classification of the formulations produced ${ }^{12}$ This classification divides the drugs into five different levels according to the organ or system over which they act and according to their chemical, pharmacological and therapeutic properties.

The investigation of the technical conditions of pharmaceutical adequacy was carried out by evaluating the Standard Operating Procedures according to the current literature .

The activity-based financing technique $(\mathrm{ABC})$ was used to calculate the costs of adapting pharmaceutical forms at the hospital evaluated ${ }^{13}$. The database of the National Sanitary Surveillance Agency ${ }^{14}$ and the national retail market were consulted to estimate the costs related to permanent materials used during manipulation, such as mortar and pestle, test tube, beaker, among others, in addition to the disposable material used as Personal Protective Equipment (PPE) such as masks, gloves and caps that are used in each manipulation.

The costs corresponding to the pharmacist workforce responsible for making the manipulations was estimated through consultation in the Transparency website of the Government of the State of Amazonas ${ }^{15}$. The approximate cost of one hour of work of a pharmacy professional was calculated using as reference the average salary paid in January 2016 to pharmacists in the unit of study, and considering that it takes an average of at least one hour to carry out the manipulations.

The inputs needed to produce each adapted item were listed based on the Standard Operating Procedures, as well as the quantity and volume consumed for each adaptation. Retail market was researched and the webpage Price Consultation - ANVISA ${ }^{14}$ was consulted to estimate the costs to produce the formulations. Expenditures on medicines and miscellaneous materials were then calculated.

The existence of alternatives available in the national market was verified through consultation of available Medications-ANVISA ${ }^{16}$, and this was compared with the items produced in the hospital. The formulation costs that represent possible alternatives were compared to the costs of adapting the medicines through the consultation of Available Medications ${ }^{16}$ and consulting prices ${ }^{14}$. The comparison was made based on the agent involved: Alternative and adaptation with equal concentrations (Midazolam and Potassium Chloride): Comparison of costs by volume; and Alternative and adaptation with different concentrations (Oseltamivir and Dexamethasone): Comparison of cost of dose using as reference the standard treatment of a 5-year-old child (approximately $18 \mathrm{~kg}$ ). The dose of oseltamivir was calculated considering the treatment dose for influenza ${ }^{17}$ $(45 \mathrm{mg})$ in a 5 -year-old male child (approximately $18 \mathrm{~kg})^{8}$. The dose of dexamethasone was calculated considering the medicine dose used to treat several inflammatory processes $(0.1 \mathrm{mg} / \mathrm{kg})$ in a 05 -year-old male child (approximately $18 \mathrm{~kg})^{8}$. The data collected was recorded in a Microsoft Office Excel 2007 spreadsheet. The desired results were obtained through graphs and tables. As the study uses only formulation data and does not involve personal or clinical patient data, there was no need for approval of the proposal by the Research Ethics Committee. As the data to be evaluated belong to the records of the Hospital Pharmacy Department, the data collection began only after the consent granted by the referred hospital.

\section{RESULTS}

Diuretics were the pharmacological class most frequently adapted. The four items spironolactone, furosemide, hydrochlorothiazide and the combination of spironolactone and hydrochlorothiazide make up this group. As for the pharmacological class most produced, the class of Diuretics had the highest production, considering the units produced, representing $27 \%$ of the total.

Due to the large dose variability of the drugs, mainly in the pediatric population, the results regarding drug transformation were exposed in volume units $(\mathrm{mL})$. Electrolytic potassium chloride had the highest production $(12,700 \mathrm{~mL})$, followed by spironolactone and hydrochlorothiazide $(10,590 \mathrm{ml})$. On the other hand, the comparison of the demand based on the production of bottles showed that the spironolactone and hydrochlorothiazide were diuretics most frequently recorded (162 units), followed by potassium chloride 6\% (139 units). These two preparations corresponded to $21 \%$. Of the total products found, only one formulation was not included in the surveys because it was a semi-solid pharmaceutical form (miconazole ointment, retinol and Medium Chain Triglycerides enriched with essential fatty acids - MCT/ EFA). This item had a total production of 63 pots in the evaluated period. It is noteworthy that this transformation is only carried out when there is a lack of zinc oxide ointment and, therefore, the adaptation was only carried out in the months of July and November of the year selected (Table 1).

A total of 378 records of formulations were found, of which 37 corresponded to the transformation oflorazepaminto syrup, corresponding to approximately $10 \%$ of the total available records.

According to the production record and the information of each Standard Operating Procedure (SOP), it was found that four different dosage forms were produced during the year: syrup, suspension, solution and ointment. Looking for the data on the total number of bottles, it was found that the pharmaceutical form syrup was the most produced (85\%).

As a result of the evaluation of the technical conditions where the pharmaceutical adaptation is made, it was observed that all the medicines submitted to adaptation had SOPs available for consultation in the Hospital Pharmacy Department and among the 28 SOPs verified, three did not present bibliographical references, namely, amlodipine syrup, potassium chloride syrup and ointment containing the combination of miconazole, 
retinol and MCT/EFA. Glass ampules are used for the adaptation of three liquid formulations for oral use: dexamethasone, furosemide and midazolam (syrups). Stability (shelf-life) and storage recommendations of the formulations are indicated in the label. The bottles used in the process were reused, and after the last use, they were washed with neutral detergent and sterilized in autoclave. There is no updated Standard Operating Procedure describing these procedures, neither differentiated identification of high-alert medications.

Table 1. Production based in volume and units of the therapeutic agents adaptation in pharmaceutical forms.

\begin{tabular}{|c|c|c|}
\hline Medicine & Volume $(\mathrm{mL})$ & Units \\
\hline Potassium chloride 6\% (syrup) & $12700(19.1 \%)$ & $150(9.8 \%)$ \\
\hline $\begin{array}{l}\text { Spironolactone + Hydrochlorothiazide } \\
\text { (syrup) }\end{array}$ & $10590(15.9 \%)$ & $174(11.4 \%)$ \\
\hline Spironolactone (syrup) & $7120(10.7 \%)$ & $112(7.3 \%)$ \\
\hline Captopril (suspension and syrup) & $5600(8.4 \%)$ & $80(5.2 \%)$ \\
\hline Carvedilol (syrup) & $4800(7.2 \%)$ & $108(7 \%)$ \\
\hline Hydrochlorothiazide (syrup) & $3420(5.1 \%)$ & $80(5.2 \%)$ \\
\hline Potassium citrate + citric acid (solution) & $3199.5(4.8 \%)$ & $38(2.5 \%)$ \\
\hline Methadone (syrup) & $2550(3.8 \%)$ & $114(7.4 \%)$ \\
\hline Topiramate (syrup) & $2470(3.7 \%)$ & $72(4.7 \%)$ \\
\hline Lorazepam (syrup) & $2392(3.6 \%)$ & $133(8.7 \%$ \\
\hline Ciprofloxacin (syrup) & $2020(3.0 \%)$ & $76(5.0 \%)$ \\
\hline Baclofen (syrup) & $1990(3.0 \%)$ & $64(4.2 \%)$ \\
\hline Furosemide (suspension and syrup) & $1540(2.3 \%)$ & $44(2.9 \%)$ \\
\hline Midazolam (syrup) & $1275(1.9 \%)$ & $63(4.1 \%)$ \\
\hline Ursodeoxycholic acid (syrup) & $1145(1.7 \%)$ & $41(2.7 \%)$ \\
\hline Nitrofurantoin (syrup) & $800(1.2 \%)$ & $21(1.4 \%)$ \\
\hline Propranolol (syrup) & $800(1.2 \%)$ & $22(1.4 \%)$ \\
\hline Nitrazepam (syrup) & $400(0.6 \%)$ & $14(0.9 \%)$ \\
\hline Sildenafil (syrup) & $390(0.6 \%)$ & $20(1.3 \%)$ \\
\hline Dexamethasone (syrup) & $370(0.6 \%)$ & $11(0.7 \%)$ \\
\hline Diazoxide & $350(0.5 \%)$ & $4(0.3 \%)$ \\
\hline Oseltamivir (solution) & $230(0.3 \%)$ & $11(0.7 \%)$ \\
\hline Fluconazole (syrup) & $165(0.2 \%)$ & $13(0.8 \%)$ \\
\hline Amlodipine & $125(0.2 \%)$ & $3(0.2 \%)$ \\
\hline Sodium bicarbonate (syrup) & $100(0.2 \%)$ & $1(0.1 \%)$ \\
\hline Total & $\mathrm{N}$ & $\mathrm{N}$ \\
\hline
\end{tabular}

In the review of the list of medicinal products subject to adaptation, four items were identified in the list of potentially hazardous medicinal products for hospital and outpatient use $\mathrm{e}^{10}$. The reasons for inclusion in the list refer to the presentation in the bulletin, where medicines are presented in a specific way or through its therapeutic classes. The drugs included in the Ordinance no 344 of $12 / 05 / 1998$ and updates ${ }^{11}$ as substances and medicines subject to special control were also identified, as shown in Table 2.

Table 2. High-alert medications subject to special control submitted to adaptation of pharmaceutical forms ${ }^{10,11}$

\begin{tabular}{lll}
\hline Medicine & $\begin{array}{l}\text { Reason for inclusion in the } \\
\text { ISPM list }\end{array}$ & $\begin{array}{l}\text { List and class subject to } \\
\text { special control }\end{array}$ \\
\hline Methadone & Oral opioid analgesic & List A1 - Narcotic substances \\
Lorazepam & Oral sedative of moderate action & $\begin{array}{l}\text { List B1 - Psychotropic } \\
\text { Substances }\end{array}$ \\
Nitrazepam & Oral sedative of moderate action & $\begin{array}{l}\text { List B1 - Psychotropic } \\
\text { Substances }\end{array}$ \\
Midazolam * & $\begin{array}{l}\text { Liquid midazolam for sedation } \\
\text { of children }\end{array}$ & $\begin{array}{l}\text { List B1 - Psychotropic } \\
\text { Substances }\end{array}$ \\
\hline
\end{tabular}

* ISPM: Institute of Safe Practices in the Use of Medications

The costs related to permanent materials used in the adaptation process were estimated at $\mathrm{R} \$ 33.56$. The approximate value of disposable materials ( $R$ \$ 9.15) and the workmanship of the professionals who perform the manipulation process $(\mathrm{R} \$ 41.72)$ was equivalent to each day of manipulation, and can occur 1 to 2 times in the same week including several preparations. The bottles used come from donations and are not purchased by the hospital. Calculations to estimate adaptation costs refer to medicines that have alternatives available on the market (Table 3):

Table 3. Cost of adaptation of therapeutic agents with possible alternatives in the national market.

\begin{tabular}{lcc}
\hline Medicine & Cost of adaptation & Volume produced \\
\hline Potassium chloride 6\% (syrup) & $\mathrm{R} \$ 2.27$ & $100 \mathrm{~mL}$ \\
Midazolam 2mg / mL (syrup) & $\mathrm{R} \$ 35.46$ & $75 \mathrm{~mL}$ \\
Oseltamivir 15mg / mL (solution) & $\mathrm{R} \$ 93.26$ & $30 \mathrm{~mL}$ \\
Dexamethasone $1 \mathrm{mg} / \mathrm{mL}$ (syrup) & $\mathrm{R} \$ 30.10$ & $100 \mathrm{~mL}$ \\
\hline
\end{tabular}

It was identified that from the twenty-eight formulations produced in the hospital, four have alternatives available in the national market for public procurement. The results of the comparison between adaptation costs and acquisition costs of ready-made formulations are shown in Table 4:

Table 4. Comparison between adaptation costs and acquisition costs of ready-made formulas.

\begin{tabular}{llll}
\hline Adapted formulation & Industrialized formulation & $\begin{array}{c}\text { Cost of } \\
\text { adaptation }\end{array}$ & $\begin{array}{c}\text { Cost of } \\
\text { acquisition }\end{array}$ \\
\hline $\begin{array}{l}\text { Potassium chloride } \\
60 \mathrm{mg} / \mathrm{mL} \text { (syrup) }\end{array}$ & $\begin{array}{l}\text { Potassium chloride } \\
60 \mathrm{mg} / \mathrm{mL} \text { (oral solution) }\end{array}$ & $\mathrm{R} \$ 0.02$ & $\mathrm{R} \$ 0.06$ \\
$\begin{array}{l}\text { Midazolam } 2 \mathrm{mg} / \mathrm{mL} \\
\text { (syrup) }\end{array}$ & $\begin{array}{l}\text { Midazolam } 2 \mathrm{mg} / \mathrm{mL} \\
\text { (oral solution) }\end{array}$ & $\mathrm{R} \$ 0.47$ & $\mathrm{R} \$ 1.30$ \\
$\begin{array}{l}\text { Oseltamivir } 15 \mathrm{mg} / \mathrm{mL} \\
\text { (solution) }\end{array}$ & $\begin{array}{l}\text { Oseltamivir } 15 \mathrm{mg} / \mathrm{mL} \\
\text { (suspension) }\end{array}$ & $\mathrm{R} \$ 9.33$ & $\mathrm{R} \$ 12.56$ \\
$\begin{array}{l}\text { Dexamethasone } 1 \mathrm{mg} / \\
\mathrm{mL}(\text { syrup) }\end{array}$ & $\begin{array}{l}\text { Dexamethasone } 0.1 \mathrm{mg} / \mathrm{mL} \\
\text { (elixir) }\end{array}$ & $\mathrm{R} \$ 0.54$ & $\mathrm{R} \$ 1.08$ \\
\hline
\end{tabular}




\section{DISCUSSION}

The study evaluated different factors related to drug manipulation and revealed that there are some ready-made formulations on the market that could replace the process of adaptation, but which are not purchased for use in the unit studied. The transformation of captopril represented $5.1 \%$ of the whole annual production in the two forms produced: syrup and suspension. This agent was described as one of the most frequently unlicensed form prescribed in a study conducted in the health unit target of the present study ${ }^{8}$, since it is indispensable for pediatric patients in treatment of cardiovascular diseases.

The survey of the number of records of manipulations revealed that lorazepam is also one of the agents with the highest demand in the hospital, with individual production, but in smaller volumes at each manipulation (an average of $60 \mathrm{~mL}$ ). This result is due to the time the medicine can be stored in the refrigerator for seven days, resulting in manipulation of the agent several times. Regarding clinical use, lorazepam is classified by Costa as a drug used in an unlicensed or restricted form in children.

In a survey conducted by Costa ${ }^{5}$, baclofen, captopril, spironolactone, diazepam, hydrochlorothiazide and propranolol were considered necessary agents in the liquid oral dosage form by the pediatricians interviewed. Thus, there is a common aspect among the hospitals evaluated in the sense of alerting to the need for development of ready-made formulations in order to care for the patients.

As regards the aspects related to technical manipulation conditions, the Standard Operating Procedures have bibliographic references and use books related to formulations of liquid formulas and scientific articles. Some procedures had been modified in the Pharmacy, including substitution of excipients (glycerol by carboxymethylcellulose - CMC), adaptation of volumes, change of concentrations of the medicine used in the formulation, change of the final concentration of the formulation, change of storage temperature, and so forth. There are three formulations produced from drugs stored in glass ampoules (dexamethasone, furosemide and midazolam). This practice is not recommended because it poses risks to patients' safety as some glass fragments may remain in the formulation. Furthermore, there is no recommendation for plastic ampoules use or filtration processes in this type of adaptation in the Standard Operating Procedures available, which could reduce the risks of this procedure ${ }^{18}$. The labeling of products handled must indicate the expiration date and storage recommendation, as well as product identification, date of manipulation and batch number as specified in legislation ${ }^{19}$. In the present study, all labels contained such information.

According to the Institute for Safe Practices in the Use of Medicines ${ }^{10}$, differentiated identification of potentially hazardous medicinal products, especially those requiring administration tools (e.g. syrups), is recommended because of the serious consequences of incorrect use of these therapeutic agents. On the other hand, the labels produced did not present differentiated identification, thus contributing to medication errors.

According to the legislation ${ }^{11}$, there should be a specific logbook for stock, entry, exit (by sale, distribution or processing) and loss of drugs subject to special control. Registration occurs only when medicine is distributed for patients, taking note of the exit of bottles of the medicine already processed and filing the medical prescription.

In the evaluation of the processes related to the manipulation of each formulation in the Standard Operating Procedure compared to the information contained in the Brazilian Pharmacopoeia' ${ }^{9}$, it was verified that most of the procedures, such as storage conditions and solubility, are in accordance with the literature.

An important point evaluated was the availability of options for patients with special needs, as for example, diabetic patients ${ }^{20}$. There have been reports of the manipulation of syrups for diabetic patients using aspartame instead of sucrose in its formulation. However, in the year evaluated, there was no production of this syrup or instructions in the SOPs. On the other hand, the formulations containing simple syrup as vehicle present the information "contains sugar" to alert the users.
Nunes ${ }^{7}$ characterized the pharmaceutical adaptations of high-alert medications as agents that require special attention to avoid risks to patient health. Errors in the use of these medications can have serious consequences, even death ${ }^{10}$. However, in view of the demand of the therapeutic agent, it is understood that a transformation is necessary and different identifications are indispensable to minimize possible errors related to the administration of these drugs, such as dosage-related errors, drug interactions, allergic conditions, adverse reactions, preparation or manipulation, among others ${ }^{21}$.

Although there are reports that other therapeutic agents such as fluconazole have a liquid form, no active registrations of these products were found on the ANVISA - Medication Consultation page ${ }^{16}$; these formulations were previously registered but are not currently available. The therapeutic agent nitrofurantoin had one registration of an oral suspension on the Medication Consultation page, but there is no price available on the Price List for public purchases ${ }^{14}$. This may mean the non-production of this drug currently. Although midazolam appears on the Hospital standardization list in the pharmaceutical form of oral solution, adaptation is necessary when this formulation is lacking. Even so, midazolam was adapted for 4 months and this may reveal some difficulty in maintaining the stocks of this drug.

Of the twenty-eight formulations produced in the hospital, four have alternatives available for purchase in the domestic market. Of the four drugs assessed for cost of adapting dosage forms, all had a financial advantage compared to the cost of acquiring the liquid formulation. The low demand of most of these ready-made agents associated with difficulties in purchasing by the public service has probably led to the decision of using the pediatric adaptation.

On the other hand, the liquid formulation of potassium chloride, despite having higher acquisition costs than the costs of adaptation, may represent an advantageous alternative if other factors such as treatment quality, safety and efficacy are considered, as a large volume of the agent is used in the Hospital.

Although the costs of acquiring the dexamethasone and oseltamivir are less advantageous than the costs of adapting the pharmaceutical form, the acquisition would be following the same point of view of acquisition of the potassium chloride formula, despite the low demand.

The agents risperidone, albendazole, amiodarone and cetirizine, with exception of risperidone, were evaluated in a comparative study of costs between transformation of pharmaceutical forms and industrialized formulations performed at a hospital in Natal- $\mathrm{RN}^{3}$. All industrialized formulations proved to be more advantageous financially in comparison to the costs of adapting it in a pharmaceutical way.

It is important to consider that pharmaceutical adaptations in the hospital are performed without quality control of the process; physical-chemical and microbiological analysis are necessary. It is also necessary to verify and solve the nonconformities in the manipulation process in order to ensure that the treatment be carried out without damage to patients' health. The study has some limitations. For example, the research was retrospective and, therefore, typical problems of a study of this nature are present here. Moreover, the complete evaluation of advantages of purchasing ready-made formulations would involve several factors other than those listed in this study, as for example the costs of quality control analyses.

\section{CONCLUSIONS}

Adaptation of pharmaceutical forms is a common and necessary process in several hospitals mainly as a result of the lack of industrialized formulations. Studies demonstrate that most of drug dosage adjustments occur because of the unavailability of suitable pharmaceutical forms on the market.

Due to the lack of industrialized formulations for most agents, the evaluated hospital needs to adopt the pharmaceutical adaptation of various therapeutic agents. However, it is necessary to solve the nonconformities found in the process and performing the physical-chemical quality control of the formulations in order to guarantee the patient safety during treatment. 
The inclusion of ready formulations in the list of standardization of the hospital evaluated represents only a small intervention against the large number of medicines that do not have liquid formulation available for purchase, demonstrating that the development of new formulations aimed at pediatric patients is necessary not only in the hospital evaluated but in several hospitals in Brazil and the world.

\section{Finalcial Sources}

The authors did not receive any funding to carry out the study.

\section{Conflict of Interests}

The authors declare that there are no potential conflicts of interest regarding the study.

\section{Authors' Contributions}

The authors contributed equaly to the study, including conception and designing or analyzing and interpreting the data; Article writing or critical review relevant to intellectual content; Final approval of the version to be published; Responsibility for all aspects of the work in ensuring the accuracy and integrity of any part of the work.

\section{Acknowledgments}

The authors thank the Institute of Children's Health of Amazonas (ICAM) for the consent to carry out the study in the dependencies of said health unit.

\section{REFERENCES}

1. Paula CS, Souza MN1, Miguel MD et al. Uso off label de medicamentos em crianças e adolescentes. Revista de Ciências Farmacêuticas Básica e Aplicada, 2011, 32(2):217-223.

2. Saavedra IS, Quinones LS, Saavedra MB et al. Farmacocinética de medicamentos de uso pediátrico, visión actual. Revista Chilena de Pediatria, 2008, 79(3):249-258.

3. Costa PQ Rey LC, Coelho HLL. Prescrição e preparo de medicamentos sem formulação adequada para crianças: um estudo de base hospitalar. Rev Bras Cienc Farmac, 2009, 45(1).

4. Corny J, Label D, Bailey B et al. Unlicensed and Off-Label Drug Use in Children Before and After Pediatric Governmental Initiatives. The Journal of Pediatric Pharmacology and Therapeutics, 2015, 20(4).

5. Costa PQ, Rey LC, Coelho HLL. Carência de preparações medicamentosas para uso em crianças no Brasil. Jornal de Pediatria, 2009, 85(3).

6. Anvisa. Como a Anvisa vê o uso offlabel de medicamentos. Disponível em: <http://www.anvisa.gov.br/medicamentos/registro/registro_ offlabel.htm> Acesso em: 25 dez 2016 às 21:40. Brasília, 2005.

7. Nunes MS, Valença RCA, Gurgel RKC et al. Análise das solicitações de comprimidos adaptados para pacientes críticos de um Hospital Universitário. Rev. Bras. Farm. Hosp. Serv. Saúde São Paulo, 2013, 4(4):23-30.

8. Gomes VP, Da Silva MK, Chagas OS et al. Off-label and unlicensed utilization of drugs in a Brazilian pediatric hospital. Farmácia Hospitalaria. 2015, 39(3):176-180.

9. Agência Nacional de Vigilância Sanitária (Brasil). Formulário
Nacional da Farmacopeia Brasileira. 2. ed. Brasília-DF: Anvisa, 2012.

10. Instituto para Práticas Seguras no Uso de Medicamentos (ISMPBrasil). Medicamentos potencialmente perigosos de uso Hospitalar e ambulatorial - Listas Atualizadas 2015.v. 4. n. 5, 2015. Disponível em: <http://www.ismp-brasil.org/site/wp-content/ uploads/2015/12/ V4N3.pdf> Acesso em 01 fev 2017 às 12:30.

11. Agência Nacional de Vigilância Sanitária (Brasil). Portaria n. ${ }^{\circ}$ 344, de 12 de maio de 1998. Aprova o Regulamento Técnico sobre substâncias e medicamentos sujeitos a controle especial. Diário Oficial da União 12 mai 1998;Seção 1.

12. Who Collaborating Centre for Drug Statistics Methodology. ATC/ DDD Index 2016. Disponível em: <http://www.whocc.no/atc/ structure_and_principles $>2011$. Acesso em 28 out 2016 às 20:40.

13. Wernke, R. Custeio baseado em atividades (ABC) aplicado aos processos de compra e venda de distribuidora de mercadorias. Revista contabilidade \& finanças, 2005, 38:74-89.

14. Agência Nacional de Vigilância Sanitária (Brasil). Consulta Lista de Preço de Medicamento. Outubro, 2016. Disponível em: $\quad<$ http://portal.anvisa.gov.br/consulta-lista-de-preco-demedicamento $>$ Acesso em 15 novembro 2016 às 21:00.

15. Portal da Transparência do Estado do Amazonas. Disponível em: <http://www.transparencia.am.gov.br> Acesso em 30 jan 2017 às $10: 27$.

16. Agência Nacional de Vigilância Sanitária (Brasil). Consulta de Produtos - Medicamentos. Disponível em: <http://www7. anvisa.gov.br/datavisa/consulta_produto/Medicamentos/ frmConsultaMedicamentos.asp > Acesso em 14 novembro 2016 às $21: 16$

17. Micromedex Solutions. Disponível em: <https://www. micromedexsolutions.com> Acesso em 03 fev 2017 às 19:15.

18. Caldwell NA, McClellan LM. Drug administration - Problems arising from glass ampoules. The Pharmaceutical Journal, 2000, 264(7094): 658-2000.

19. Agência Nacional de Vigilância Sanitária (Brasil). RDC nº. 67, de 08 de outubro de 2007. Dispõe sobre boas práticas de manipulação de preparações magistrais e oficinais para uso humano em farmácias. Diário Oficial da União 9 out 2007; Seção 1.

20. BalbaniAPS, Stelzer LB, Montovani JC. Excipientes de medicamentos e as informações da bula. Revista Brasileira de Otorrinolaringologia, 2006, 72(3):400-406.

21. Luedy A, Sousa ARS, Sacramento BIL et al. Estratégias para prevenir erros na administração de medicações de alta vigilância. Revista Acreditação, 2011, 1(2): 93-110. 